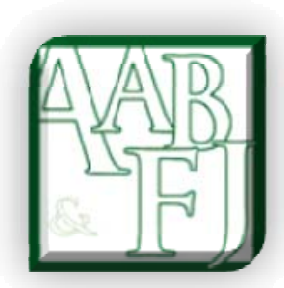

\title{
Alternative Representation of Management Control Design: an empirical exploration and critical analysis
}

Jim Rooney, University of Sydney *

\begin{abstract}
This paper describes a critical analysis of three recently published theoretical frameworks developed to explain management control design within inter-organisational collaborations. The particular concern is that, despite a plethora of theoretical frameworks attempting to explain management control design choices, these frameworks have yet to be utilised in practice. The focus is on their respective ability to explain control change in response to coordination problems, recognising the interactive nature of inter-organisational relationships. It adopts an approach previously used in the accounting literature for the purpose of promoting discussion and critical reflection. The resulting case study analysis provides critical insight on how each of the frameworks can influence discipline-specific understanding of control evolution. Improved understanding is expected to indicate potential usefulness to accounting practice. Hence, within inherent limitations, the paper reflects on opportunities to consolidate extant management accounting theory.
\end{abstract}

Keywords: Management Control; Outsourcing; Coordination; Critical Reflection; Inter-organisational Relationships; Accounting Theory

JEL Code: M40

Acknowledgement:

Many thanks to Dr Jane Andrew for feedback, encouragement and advice on earlier drafts of the paper. However, all errors and omissions are attributable entirely the author.

*jim.rooney@sydney.edu.au 


\section{Introduction}

The need for empirical study of antecedents of management control change is acknowledged in the accounting literature (Anderson \& Dekker 2005). In spite of extensive literature, there has been mixed progress in explaining control practice (ASCPA Australia 2005), characterised as an "inconclusiveness [that] is even more severe if we consider that the findings proposed by contributors are in some cases contradictory." (Caglio \& Ditillo 2008, p. 874).

Examination of this trend is important, timely and is motivated by recognition that accounting research to date has consumed significant effort in establishing theoretical frameworks that have received little or no recognition in practice. From a theoretical perspective, a number of these frameworks are based on similar antecedent constructs (Caglio \& Ditillo 2008). Consequently, there is an opportunity to examine the degree to which alternate frameworks provide understanding of management control evolution within interorganisational relationships. Echoing Luft and Shields (2002, p. 24):

".. if these different sets of variables describe the same phenomena from the viewpoint of different theories that divide up and name the phenomena differently, there is more reason for research in one stream to take account of analysis and evidence produced by research in other streams".

The paper has one key objective, namely, deeper understanding of the relative efficacy of extant management control frameworks in describing the dynamics of management control design change in practice. Given a reflective approach, the paper will not attempt to confirm causal links between the management controls implemented in response to coordination problems. The resulting critique attempts to transcend finding fault with extant management control theory, offering insights by identifying, challenging and examining the manner in which alternate management control theory translates into practice (Alvesson \& Deetz 2000).

The next section of the paper provides a summary of the academic literature associated with management coordination problems. The third section of the paper summarises the research method, with results obtained presented in the fourth section. Critical analysis of the findings, including avenues for future research opportunities, is discussed in the final section of the paper.

\section{Management Control Frameworks}

\section{A Summary of the Coordination Literature}

Given increased complexity and the pluralist nature of inter-organisational relationships, an increased interest in coordination is found in various literature, including supply chain (Danese et al. 2004; Holweg \& Pil 2008) and organisational science (Hong et al. 2009). Calls within the organisational science literature draw attention to the importance of work design, both within and between organizations (Barley \& Kunda 2001). Recognising emerging trends in work practices associated with information intensity, globalisation, technology and inter-organisational collaboration, for example, Sinha and Van de Ven (2005) highlight a need to refocus research on work design affected (and affecting) interactions between work units. Hence, a focus on coordination.

Coordination in the organisational science literature is focused on resolving task dependencies within a work setting (Crowston 1997; Malone \& Crowston 1994). The primary research interest has been, until recently (Hong et al. 2009), on identifying substitutable coordination mechanisms and determining which mechanism applies to specific circumstances (see Thompson 1967; Galbraith 1977; Mintzberg, 1979). This literature 
addresses the "structure" by which behaviours are programmed as well as the "process" by which adjustments are made in light of new information (Argote, 1982). Accordingly, the theoretical frameworks explored here include coordination as an antecedent for adoption of management controls. In support of this approach, "focusing on control problems could produce benefits both in the literature development and in the completeness of the description and interpretation of reality” (Caglio \& Ditillo 2008, p. 891).

\section{Coordination Control Problems}

Building on research by Dekker (2004, 2008), the paper adopts a multi-dimensional view of the antecedents of coordination control problems. Often understood in terms of Contingency Theory, coordination control problems are related to realisation of a lack of clear interorganisational relationship boundaries. The result is failure to achieve the relationship outcomes agreed by the parties to a "level of mutual satisfaction" (Caglio \& Ditillo 2008, p. 891). To that end, management control constructs used in this paper are based on prior academic literature, recognising theoretical advances to date and improving the likelihood of comparison between research streams.

Based on the extant literature, operationalisation of the antecedents for coordination problems is focussed on three constructs, namely: task characteristics, task environment and interdependence. In summary, task characteristics in an inter-organisational context are concerned with task complexity (Dekker, 2004, 2008) and programmability (Spekle 2001). Task environment is influenced by reputation (Tomkins 2001), relative bargaining power (Donada \& Nogatchewsky 2006) and the degree to which both parties to the transaction agree that power and relevant information have been shared as a result of the transaction (Kammonga \& Meer-Kooistra 2007). Interdependence is largely driven by the degree to which buyer and supplier services are related to one another, increasing the impact of transaction complexity (Dekker 2008), contractual commitment (Poppo \& Zenger 2002) and values integration (Goles \& Chin 2005).

\section{Management Control Frameworks}

Recent literature reviews on inter-organisational management control point to use of a diverse range of theoretical perspectives (Vosselman \& Meer-Kooistra 2006). Given the existence of detailed attempts to describe and categorise this research (see Caglio \& Ditillo 2008), details are not repeated here. Based on an approach to "good theory" outlined by Levie and Lichtenstein (2008, three management control frameworks are identified for comparison. Whilst far from exhaustive, the frameworks selected here represent the development of management control theory addressing predefined criteria. ${ }^{1}$

Two papers from the 2008 Accounting Organization \& Society (AOS) special edition on management control and one published in Management Accounting Research (MAR) in the same year provide sources for the three management control frameworks used in the paper:

- Management Control Archetypes - a multi-theory perspective focussed on emergence of control problems (Caglio \& Ditillo 2008);

- Management Control Packages - focussed on the practice of combining of controls into "packages" (Malmi \& Brown, 2008);

- Trust-Building Management Control- based on a synthesis of the extant trustbuilding literature (Vosselman \& Meer-Kooistra, 2008).

\footnotetext{
1 The key criteria are coverage of a range of control types across a range of perspectives from the accounting literature (e.g. formal and informal; market and bureaucratic); alignment with relationship problems; published in leading accounting journals in 2008/9 using current research; and the use of theory based approach based on multi-disciplinary constructs.
} 
Alternate accounting research on theory-building to explain inter-organisational controls tends to focus on specific aspects such as alliance partner selection (for example, Dekker 2008), a single level of analysis such as strategic (Simons 1990) or one type of control such as trust (Langfield-Smith 2008; Velez et al. 2008). With this in mind, management control mechanisms associated with the selected frameworks are outlined next.

\section{Management Control Mechanisms}

In each of the control frameworks examined here, a range of formal and informal control mechanisms are adopted in response to the emergence of control problems. Research highlighted earlier provides a basis for examination of the adoption of key control mechanisms found in a post-contractual relationship. As a result, management controls comprises the following mechanisms:

Table 1: Summary of management control mechanisms

\begin{tabular}{|l|l|}
\hline Control Mechanism & \multicolumn{1}{l|}{ Description \& Source } \\
\hline Behaviour Controls & $\begin{array}{l}\text { Controls directed at guiding behaviour, excluding changes to } \\
\text { contract terms associated with these items (Dekker 2004) }\end{array}$ \\
\hline Outcome Controls & $\begin{array}{l}\text { Quantitative measures, standards and feedback processes, } \\
\text { excluding changes to contract terms (Dekker 2004) }\end{array}$ \\
\hline Contract Controls & $\begin{array}{l}\text { Clauses included in the design and modification to the terms of the } \\
\text { outsourcing contract developed and formally agreed by both } \\
\text { parties (Vosselman \& Meer-Kooistra 2008) }\end{array}$ \\
\hline Social Controls & $\begin{array}{l}\text { "Management control practices targeting minds, through norms, } \\
\text { emotions, beliefs and values, are intended to affect behaviour } \\
\text { indirectly." (Alvesson \& Karreman 2004, p. 425; also Dekker } \\
\text { 2004) }\end{array}$ \\
\hline Market Controls & $\begin{array}{l}\text { Market alternatives to guide behaviour including credible threats } \\
\text { of substitution with alternate suppliers for part/all of in-scope } \\
\text { services }\end{array}$ \\
\hline
\end{tabular}

\section{Critical Analysis Framework}

As this paper takes a critical research perspective, its main focus is to seek greater understanding and identify opportunities to develop the management accounting concepts discussed here. The paper adopts an approach articulated by Alvesson and Deetz (2000, pp. 17-20), outlining three tasks of critical research: 'insight', 'critique' and 'transformative redefinitions'. Similar approaches are adopted in the accounting literature, particularly in research on Intellectual Capital (Dumay 2009) and public sector accounting (Laughlin 1995). Each of these tasks is discussed from a dynamic inter-organisational management control perspective.

Insight

Alvesson and Deetz (2000, p. 17) identify the task of 'insight' as being to demonstrate "our commitment to the hermeneutic, interpretive and ethnographic goals of local understandings closely connected to and appreciative of the lives of real people in real situations”. From a management control perspective, insight involves attempts to understand the impact of control practices on both human actors and their organisations, helping to provide new perspectives on questions of how management control works between firms and what comprises control. 
Whilst not explicitly based on Middle-Range Theory and German critical thinking as described by Laughlin (1995) ${ }^{2}$, the critical analysis approach adopted here shares the aim of providing an opportunity for researchers to make known "what we are doing and why we are doing it" (Laughlin 1995, p. 78). It allows outcomes of the critical analysis to be communicated, being an open theoretical model supporting a range of methods and recommendations for change that are based on practice and include the researcher as part of the discovery process (Laughlin 1995). Thus, a performative approach, recognising "that there is no fundamental formula to understanding the role of management control in organization and society” (Mouritsen 2006, p. 823) is selected as the critical perspective used here.

Critique

The objective of critique "is to counteract the dominance of taken-for-granted goals, ideas, ideologies and discourses which put their imprints on management and organization phenomena" (Alvesson \& Deetz 2000, p. 18). It is argued that a critique of management control frameworks is needed given that, whilst changing in recent years to reflect sociological constructs in particular, one of the problems of contemporary accounting theory is the adoption of ideas and terminology sourced from traditional management thinking. The proliferation of contemporary management control frameworks attempting to describe the phenomenon provides tangible evidence of this thinking (Caglio \& Ditillo 2008).

\section{Transformative redefinition}

The final step of the critique "is the development of critical, managerially relevant knowledge and practical understandings that enable change and provide skills for new ways of operating” (Alvesson \& Deetz 2000, p. 19). Key to management control dynamics, inherent contradictions in espoused benefits of management control and the reality of organisational practices are highlighted. These contradictions are intended as opportunities to develop insights that influence future management practices (Alvesson \& Deetz 2000).

\section{Research And Sites}

\section{Case Studies}

The unit of analysis for the purposes of this paper is both the outsourcing transaction and the back-office operations domain within an outsourcing relationship. Buyer and supplier points of view were explored. The proposed field study includes a collection of data from six existing outsourcing arrangements within a single industry - home loan providers in the Australian Consumer Mortgage sector. The six relationships exhibit varying levels of control design, client and servicer size, service scope and fate. This allows exploration of a clearly definable organisational boundary of the full interorganisational relationship. However, the predominant outsourcing relationship explored (i.e. four of six case studies) is between a medium-sized specialised residential real estate lender and a medium size primary (or lead) service provider supporting customer operations and technology functions.

As the participant firms are in the same industry with different inter-organisational boundaries, governance structures, controls and relationship success, a number of key variables identified in the MCS literature were controlled in order to explore governance and control variables practices (see Whang 1992; Deeds \& Hill 1998; Seal 2004). The specific

\footnotetext{
${ }^{2}$ Given the focus of the paper is practice rather than philosophy, further discussion is not included here. It can be argued, however, that nature of the inquiry in the paper is abductive as described by Pierce (1959) involving critical analysis framed by theoretical preconditions (see Crotty, 1998).
} 
control variables include industry/product competition, supplier power, asset specificity, uncertainty (or incomplete contracting) and frequency (or repetitive transaction exchange). An added advantage of the research scope is it is focused on an industry that has a long history of utilising outsourced service providers, utilising a range of formal (action and outcome based) and informal management controls.

The Outsourcing Agreement and associated operational and financial data was sourced on a non-attributable confidential basis. The outsourcing buyers were chosen as representative of the entities operating in the mortgage industry in Australia that have developed and implemented management control associated specifically with Outsourcing Agreements they have been party to. All are unlisted non-government enterprises. Some are subsidiaries of publically listed companies. Table 2 summarises sources of governance documentation analysed.

Table 2: Case study dimensions - summary of governance document scope

\begin{tabular}{|c|c|c|c|c|c|c|c|}
\hline Document Type & $\frac{\pi}{\frac{\pi}{2}}$ & 胥 & छ & 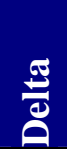 & $\frac{\overline{0}}{\frac{0}{0}}$ & Nّ & $\begin{array}{l}\text { 是 } \\
\text { 甚 } \\
0 \\
\end{array}$ \\
\hline Minutes of Meetings & 25 & 7 & 4 & 19 & 8 & 10 & 73 \\
\hline Reports & 1 & - & 4 & 1 & 4 & 5 & 15 \\
\hline Emails & 11 & - & - & - & - & - & 11 \\
\hline Other & - & - & - & - & - & 9 & 9 \\
\hline Total & 37 & 7 & 8 & 20 & 12 & 24 & 108 \\
\hline
\end{tabular}

\section{Method}

The initial phase of research involves coding analysis (see Krippendoff 1980). Data includes contract and related contractual control material, governance material such as governance meeting minutes and agreed reporting artifacts gathered along with operational performance reporting achieved by respective outsourcing service providers. The initial analysis is followed by semi-structured interviews. As a result, the paper will examine key stakeholder perceptions of management control design for the overall interorganisational relationship. The methodological approach is conducted in line with the work of Birnberg et al. (1990) where multiple research methods are used to gather and triangulate empirical data. The above methods yields results which helps explore the extent to which each control framework fits observed data.

\section{Results}

A key buying criteria in all six outsource relationships was the avoidance of investment in technology and human resources as well as reduction in operating costs. In the three cases that involved start-up buyers, the absence of capability to create and sustain these functions inhouse at the time of the transaction was also a key factor. The importance of relationship management and communication was identified early. As expressed by a buyer operations team leader: 
"Communication has not been all that effective. Need to meet on a more regular basis, aside from emails, particularly now that there are 2 new teams actioning the settlements and servicing functions"

Recognition of inter-organisational communication gaps is an important driver for adoption of joint analysis activities to address coordination problems emerging in all six relationships. Joint problem analysis was, in turn, a significant aspect in the evolution of management control, used to help drive greater process coordination. For example, in one case, there was informal recognition that outsourcing strategy was evolving to focus on improved customer service with willingness to trade-off improvements in customer service for increased service cost. Strategy evolution was responding to emerging customer requirements identified through marketing focus groups and regular customer surveys conducted by the buyer entity over time. The relationship saw increased use of social controls at an operational management level as an effective way of addressing coordination problems as well as supporting greater alignment with evolving customer-focussed outsourcing strategy:

"We made it a point of treating the employee of <Delta Supplier $>$ as if they were our employees. There's a fine line but we thought it was very important that we didn't have a them and us relationship."

As a result, there is evidence of increased levels of work coordination, initially at a relationship management level.

"a strong understanding by <Supplier> of what our strategy was...and the way in which we wanted to have the interaction with our customers"

With this relationship background in mind, the following results provide an overview of the findings using each of the three management control frameworks.

\section{Management Control Archetypes}

Coding analysis for the Caglio and Ditillo (2008) framework sourced from governance artefacts sourced from the six case studies is summarised in Table 3.

Table 3: Management control type results (percentage total actions by category)

\begin{tabular}{|c|c|c|c|c|c|c|c|}
\hline Keyword Subcategories & $\frac{\pi}{\frac{\pi}{2}}$ & ڤేّ & 导 & تِّ兀" & $\frac{\overline{0}}{\frac{0}{0}}$ & సँّ & 是 \\
\hline Behaviour Controls & 63 & 76 & 100 & 46 & 36 & 59 & 57 \\
\hline Contract Controls & 16 & 16 & - & 6 & 20 & 4 & 12 \\
\hline Market Controls & 1 & - & - & - & - & - & 0 \\
\hline Organisational Norms & 10 & - & - & 38 & 36 & 27 & 20 \\
\hline Outcome Controls & 9 & 8 & - & 10 & 8 & 8 & 10 \\
\hline Trust & 1 & - & - & - & - & 2 & 1 \\
\hline Total & 51 & 5 & 0 & 19 & 6 & 19 & 100 \\
\hline
\end{tabular}

As Table 3 indicates, behaviour controls are the predominant management control type over the life of the six relationships, as summarised below. 
First, all of the outsourcing relationships studied had a clear preference for implementing new behaviour controls after the contract has been signed. Two cases in particular, with additional contract controls as well as behaviour controls, were actively managing the relationship through the ongoing development of formal control mechanisms. The Gamma case was the extreme example of this pattern, adding these controls exclusively ex ante the relevant outsourcing contracts. However, the Epsilon case was a relatively lower user of these controls with use of a combination of contract and organisational norms with behaviour controls. This may have reflected preferences of individual actors with caution being suggested in adding such controls, as highlighted by the (buyer) Operations Manager:

"The tendency of the outsourcing client (is to specify the how-to) because they want to outsource but they (also) want control. It's a natural thing but it's a trap."

Second, three of the six cases made some use of the Contract Control type. The other outsourcing relationships added little or no controls of this type. The role of the contract as a frame for the relationship is partly evidenced by a (buyer) Relationship Manager:

"We took a lot of time in developing it (and) in engagement, making sure it was right."

Third, based on usage, the Organizational Norm Control types are of relatively high importance for three of the relationships. For the Epsilon case, it equalled behaviour controls, as expressed by the buyer Relationship Manager:

“... there was a fairly good mutual understanding of what was expected.”, and

" $a$ strong understanding by (the outsourcer) of what our strategy was...and the way in which we wanted to have the interaction with our customers"

Based on available data, confirmed by interview transcripts, there appears to be a low propensity to change other management controls defined within this particular theoretical framework.

\section{Management Control Packages}

The second coding framework describes management control packages described by Malmi \& Brown (2008) producing document coding summarised in Table 4.

Table 4: Management control package results (percent by subcategory)

\begin{tabular}{|c|c|c|c|c|c|c|c|}
\hline Keyword Subcategories & $\frac{\pi}{\frac{\pi}{2}}$ & ت્ّ & Ð & $\frac{\pi}{0}$ & 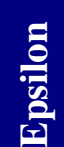 & ปัँ & 电 \\
\hline Administrative Controls & 30 & 49 & 31 & 28 & 31 & 76 & 39 \\
\hline Cultural Controls & 2 & 29 & 16 & 30 & 16 & - & 16 \\
\hline Cybernetic Controls & 6 & 2 & 3 & 11 & 3 & 12 & 9 \\
\hline Planning & 62 & 16 & 50 & 31 & 50 & 12 & 35 \\
\hline Reward \& Compensation & - & 4 & - & - & - & - & 1 \\
\hline Total & 20 & 14 & 7 & 18 & 27 & 14 & 100 \\
\hline
\end{tabular}


Examining a keyword frequency for the control package subcategories, 39\% of sentences with a control package theme (a total of 377 sentences) contained references to administrative controls. Based on keyword sentence counts, the minimum usage was exhibited by Gamma comprising 30 sentences with the maximum being Epsilon comprising 99 sentences. Planning controls are the next in frequency of use over substantive period of the relationships. Accordingly, trends indicated in Table 4 result in the following key findings:

Administrative Controls are the predominant management control element utilised by all of the six outsourcing relationships studied, along with planning controls. In particular, the Zeta case was a proportionally prolific user of procedural changes in combination with increased cybernetic and planning controls. This is despite an already high use of such controls in the original contract compared to other relationships studied. Beta was also focused on this form of control being a relatively high user of these controls. For example, a key source of coordination problems is associated with increasing complexity of the Buyer's product offering along with increasing business volume, evidenced in a year two governance meeting document:

"Further clarity to be provided over final progress payments and LMI funding ..", and "Processing requirements to be streamlined..."

The other relationships also made significant changes to these controls, tending to use them in combination with action planning, in order to address coordination problems. Changes to procedures followed by governance structures are the predominant form of postcontractual response to coordination problems for all relationships except Gamma, where organisational changes were preferred.

On the other hand, Cultural Controls were not generally seen as important with the exception of Beta and Delta, which made extensive use of such controls, complemented with simultaneous use of administrative controls. Where changes to these controls are implemented, imposition of client values and, to a lesser extent, clan controls were clearly favoured.

Cybernetic Controls represent approximately $10 \%$ of the overall changes controls. When changes are implemented, they tend to be based on non-financial measures with some limited use of hybrid metrics. No additional financial measures were implemented by any relationship. As discussed in a later section of the paper, this finding is significant.

Planning Controls are the second most significant component of change in overall management control design post-contract, with Alpha, Delta and Epsilon being the major users. Action planning is overwhelmingly in the form of change implemented for this control type with only two instances (one each for Alpha and Delta) associated with long term planning controls. These findings appear contrary to expectations in the control literature, given the relative size of the clients associated with these relationships.

Rewards \& Compensation were not a material component of the overall management control package, with Beta and Epsilon being the only relationships to add this control measure to address coordination problems.

\section{Trust Building Management Control}

The final coding framework utilised management control archetypes described by Vosselman and Meer-Kooistra (2008), as summarised in Table 5 below. 
Table 5: Trust building results (percent by subcategory)

\begin{tabular}{|c|c|c|c|c|c|c|c|}
\hline Keyword Subcategories & $\frac{\pi}{\frac{\pi}{2}}$ & 胥 & 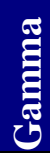 & 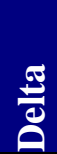 & $\frac{\overline{0}}{\frac{0}{0}}$ & తึ & 远 \\
\hline Accounting for Control & 19 & 36 & 12 & 45 & 47 & 74 & 39 \\
\hline Accounting for Trust & 81 & 64 & 88 & 55 & 53 & 26 & 61 \\
\hline Accounting for Stability & - & - & - & - & - & - & 0 \\
\hline Total & 27 & 7 & 7 & 16 & 27 & 16 & 226 \\
\hline
\end{tabular}

TT

Accounting for Control is a key management control element utilised by all of the six outsourcing relationships studied. In particular, Epsilon and Zeta were significant users of changes to governance structure in combination with a comparatively moderate increase in performance measures, in spite of the already high use of such controls in the original contract in both cases compared to other relationships studied (except Gamma). The opinions of the Epsilon (supplier) Relationship Manager suggests that this may have been associated with problems in the early years of the relationship:

"There was a high gap in expectations and...(the outsourcer) bit off something that it could not deliver and, naturally, that had a very detrimental impact on the relationship."

Beta was also focused on this form of control. The other relationships also made some changes to these controls, tending to use them in combination with action planning, in order to address coordination problems. Changes to procedures followed by governance structures are the predominant form of response to coordination problems except for Gamma.

Accounting for Trust Building is the predominant management control element utilised by all of the six outsourcing relationships studied, but in particular by Alpha, Delta and Epsilon. The dominant control is the normative frame. Whilst not strictly a control in the normal sense of that construct, this predominant frame indicates a willingness to build trust.

Accounting for Stability was not utilised based on the evidence available. These results and associated findings are discussed in more detail next.

\section{Critical Analysis, Discussion And Conclusions}

Insight

Reviewing the results of coding analysis, there are a number of key findings of interest starting with control construct similarities highlighted by Table 6 below, summarising the relative percentage (of total coded references) for each control: 
Table 6 Comparison of nominally equivalent controls (percent by control type)

\begin{tabular}{|c|c|c|c|c|c|}
\hline $\begin{array}{l}\text { MCS Type } \\
\text { Framework }\end{array}$ & 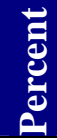 & $\begin{array}{l}\text { MC Package } \\
\text { Framework }\end{array}$ & 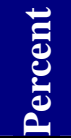 & $\begin{array}{l}\text { Trust Building } \\
\text { Framework }\end{array}$ & 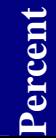 \\
\hline Behavioural & 57 & Administrative & 39 & - & - \\
\hline $\begin{array}{l}\text { Organisation } \\
\text { Norms } \\
\text { \& Trust } \\
\end{array}$ & 21 & Cultural & 16 & Trust & 61 \\
\hline Contract & 12 & Planning & 35 & Control & 39 \\
\hline Outcome & 10 & Cybernetic & 9 & & \\
\hline Market & 0 & Rewards & 1 & - & - \\
\hline - & - & - & - & Stability & 0 \\
\hline
\end{tabular}

For example, in the first row, behaviour control (MCS Type) and administrative control (MCS Package) are equivalent with similar coordination problem antecedents. The Trust building framework is not concerned with these controls. The following paragraphs address insights germane to control contracts across the three frameworks analysed.

Although largely equivalent in terms of construct and indicator definition, there is a material under-representation of Administrative Control constructs when the Management Control Package framework is compared with the equivalent under the Management Control Type framework (Behaviour Controls). In most of the relationships, use of a different coding framework will result in differences in the level of identification of post-contractual changes in formal controls. For example, using the Control Package framework, the Alpha (where 42 sentences or $46 \%$ of all changes are new Behaviour controls) and Delta (160 or 63\%) relationships indicate a material over-representation of formal control constructs when compared with the equivalent under the Control Type framework (Administrative controls occur in 23 sentences or 30\% of all control change references for Alpha and 19 sentences or $28 \%$ for Delta respectively).

Whilst generally equivalent in concept, the Control Package framework of Malmi \& Brown (2008) materially under-represents the importance of informal controls (Organisational Norm and Trust MCS types or Cultural Controls in the MCS Package framework). The effect is partly evidenced by both the number and relative proportion of sentences exhibiting the alternate management control constructs. This pattern is consistent across all relationships although most obvious when comparing the Beta and Zeta relationship where the coding results would suggest opposite conclusions. ${ }^{3}$ The insight is also consistent with the focus on social controls in the interviews with Beta and Zeta representatives, selected examples being evidenced in the results section earlier.

Whilst Outcome Controls (MCS Type) and Cybernetic Controls (MCS Package) are considered to be broadly equivalent concepts, the definitions of indicators used for Management Control Package (Malmi \& Brown 2008) appear to result in an overrepresentation of these control types. Given the low absolute number of sentences

3 The respective results being 0 vs 15 sentences (0\% vs $29 \%$ ) for Beta and 27 vs 0 sentences (29\% vs $0 \%$ ) for Zeta. 
identified for Beta, the finding may not be material for this relationship. The insight with respect to Beta is also consistent with the interviews citing lack of interest in output controls.

There is a clear difference between the Trust Building framework and the other two frameworks. In particular, trust-building activities in this framework, incorporating social controls and broader related social constructs of the other frameworks, appear to result in greater identification of informal controls. This may be the result of the adoption of constructs from cognitive psychology. It may also be the result of the data gathering techniques used for this study that are less useful to the identification and understanding of the constructs relevant to this framework. On the other hand, the combination of governance and output controls in the formal control may result in a view that there is a path dependency in inter-organisational relationships from formal to trust-based control, a progression that may not reflect the changing nature of the relationship (including regression to increased incidence coordination problems for isolated periods). These aspects are discussed later in this section.

As the above insights illustrate, a review of management control theory and practice has found definitional gaps between the espoused theory and the practice of management control within the three frameworks studied. A central issue is that while there are a plethora of theoretical frameworks developed for the measurement, management and reporting of control, these frameworks are not clearly operationalised in order to be consciously adopted by firms, despite the potential benefits. The intent of this paper has been to resist the development of new theoretical views, instead examining management control practice to develop understanding such that a discourse can be developed that increases the understanding of the dynamics of management control in practice. Doing so develops a critique of management control theory that has the potential to influence future practice. This critique is outlined below.

\section{Critique}

In light of the insights described above, critical analysis of the three frameworks identifies the following material inconsistencies at a construct level:

Whilst the theoretical source of social control constructs is comparable, wider interpretation of Organisational Norms, Trust and Clan Controls contained in the Organisational Norm construct (MCS Type) allows a consistent identification of informal styles of management control. This is reflected in the slightly higher incidence of such constructs. Conversely, trust-building constructs of the third control framework also appear to be a significant aspect of management control. Given trust building activities are intended to lead to the adoption of trust controls, they may be more readily described as an antecedent or mediating factor to trust-based controls rather than separately identified controls. The interview transcripts appear to support this interpretation, particularly for the Delta case study.

Processes associated with problem escalation, review and reporting appear repeatedly during the post-contractual management of the relationship. Related constructs such as Governance, Contract Control and Action Planning are not directly reflected in the MCS type framework except to the extent to which action planning is adopted as an initial step in address emerging coordination problems, leading to new or modified controls. Consistent with the Trust-Building framework, such activities are intended to lead to adoption of new control mechanisms and may be more readily described as antecedents to coordination problems. The Planning Control construct is unique to the MCS Package framework, allowing identification of activities specifically aimed at addressing coordination problems and/or implementing performance improvements in the relationship. As it is not separately identified in the other framework, combination of the separate construct as an antecedent or mediating factor in control evolution may be warranted rather than as a separate control. 
Finally, the more detailed categories associated with the Cybernetic Control construct used in the Management Control Package framework appear to provide a more definitive coverage of the range of performance management tools used in practice than the generic term of outcome control used in the MCS Type framework. Such detail is likely to provide greater diagnostic capability as evidenced by the coding analysis conducted for the purposes of the paper.

\section{Transformative Redefinition}

With critique of the three control frameworks studied, the following paragraphs identify opportunities for consolidation of extant control frameworks.

An opportunity exists to consolidate trust constructs with trust-building antecedents and planning/action planning as antecedents or moderating influences on the evolution of management controls. As this paper did not study normative relationships between coordination problems and control mechanisms, confirmation of linkages between antecedents, problems and management control responses is not discussed here. Following Luft and Shields (2002, p. 32), "theory-defined variables are more likely to have well-defined, stable, unitary meanings, making it possible to identify consistent cause-and-effect relations.” This is a suggested topic of follow-up research to this paper.

Whilst detailed theory building is beyond the scope of this paper, the insights and critique outlined above may be assimilated into a framework that reflects consistency in theoretical constructs between the three frameworks studied. Specifically, other theoretical framework described in the accounting literature focused on specific aspects of control such as inter-organisational partner selection (Dekker 2008) and initial post-contract control selection (Langfield-Smith 2008) can be analysed for potential to incorporate associated, largely contingent, constructs into a comprehensive control framework.

This approach, involving critical analysis of competing framework attempts to summarise the progress in the accounting literature associated with the development of multitheory, multidisciplinary typology of management control.

In closing, the limitations of the paper need to be acknowledged. First, whilst the six case studies represent approximately $25 \%$ of the consumer mortgage industry in Australia, the limited number selected places limits on the generalisability of the insights requiring further industry and geographical diversity (see Bigelow \& Argyres 2008. Secondly, a number of the theoretical constructs require refinement to account for contextual and industry-specific antecedents as well as potential mediating factors in the evolution of control mechanisms. Examples include output measurability, information asymmetry and trust building. Thirdly, the financial performance implications of utilising different control mechanisms were not examined. Fourthly, exploration of an entire network of interorganisational relationships, not identified as a significant influence in this study ${ }^{4}$, may also be a potentially fruitful line of inquiry. This expanded empirical research may address concerns of the type expressed by Fritsch et al (2007, p. 23) that "no clear conclusions on the impact of outsourcing or vertical integration on firm performance can be drawn...”. Finally, whilst partly mitigated by coding analysis and semi-structured interviews, there are limitations associated with reliance on memory and recollection by interview participants. These limitations remain opportunities for further research.

4 Although the source of some performance problems that needed to be addressed in the context of the primary relationship. 


\section{References}

Alvesson, M \& Deetz, S 2000, Doing critical management research, SAGE, Thousand Oaks, California.

Alvesson, M \& Karreman, D 2004, 'Interfaces of control. Technocratic and socio-ideological control in a global management consultancy firm', Accounting Organizations and Society, vol. 29, no. 3-4, pp. 423-444. http://dx.doi.org/10.1016/S0361-3682(03)00034-5

Anderson, SW \& Dekker, HC 2005, 'Management control for market transactions: The relation between transaction characteristics, incomplete contract design and subsequent performance', Management Science, vol. 5, no. 12, pp. 1734-1752. http://dx.doi.org/10.1287/mnsc.1050.0456

Argote, L 1982, 'Input uncertainty and organizational coordination in hospital emergency units, Administrative Science Quarterly’, vol. 27, no. 3, pp. 420-434. http://dx.doi.org/10.2307/2392320

ASCPA Australia 2005, Small Business Survey Programme - Outsourcing, ASCPA, Melbourne.

Barley, SR \& Kunda, G 2001, 'Bringing work back in', Organizational Science, vol. 12, no. 1, pp. 76-95. http://dx.doi.org/10.1287/orsc.12.1.76.10122

Bigelow, LS \& Argyres, NS 2008, 'Transaction costs, industry experience and make-or-buy decisions in the population of early U.S. auto firms', Journal of Economic Behavior \& Organization, vol. 66, no. 3/4, pp. 791-807. http://dx.doi.org/10.1016/j.jebo.2006.01.010

Birnberg, JG, Shields, MD \& Young, SM 1990, 'The Case for Multiple Methods in Empirical Management Accounting Research (With an Illustration from Budget Setting)', Journal of Management Accounting Research, vol. 2, pp. 33-66.

Caglio, A \& Ditillo, A 2008, 'A review and discussion of management control in inter-firm relationships: achievements and future directions', Accounting, Organizations and Society, doi:10.1016/jaos.2008.08.001.

Crotty, T 1998, The foundations of social research, Allen \& Unwin, St Leonards, Australia.

Crowston, K 1997, 'A coordination theory approach to organizational process design', Organization Science, vol. 8, no. 2, pp. 157-175. http://dx.doi.org/10.1287/orsc.8.2.157

Danese, P, Romano, P \& Vinelli, A 2004, 'Managing business processes across supply networks: the role of coordination mechanisms', Journal of Purchasing \& Supply Management, vol. 10, pp. 165-177. http://dx.doi.org/10.1016/j.pursup.2004.11.002

Deeds DL\& Hill CWL 1998, 'An Examination of Opportunistic Action within Research Alliances: Evidence from the Biotechnology Industry', Journal of Business Venturing, vol. 14, pp. 141-163. http://dx.doi.org/10.1016/S0883-9026(97)00069-4

Dekker, HC 2004, 'Control of inter-organisational relationships: evidence on appropriation concerns and coordination requirements', Accounting, Organizations and Society, Vol. 29, pp. 27-49. http://dx.doi.org/10.1016/S0361-3682(02)00056-9

Dekker, HC 2008, 'Partner selection and governance design in interfirm relationships', Accounting, Organizations and Society, vol. 33, pp. 915-941. http://dx.doi.org/10.1016/j.aos.2007.02.002

Donada, C \& Nogatchewsky, G 2006, 'Vassal or lord Alphas: How to exert management control in asymmetric interfirm transactional relationships?', Management Accounting Research, vol. 17, pp. 259-287. http://dx.doi.org/10.1016/j.mar.2006.06.002

Dumay, J 2009, 'Intellectual capital measurement: A critical approach', Journal of Intellectual Capital, vol. 10, no. 2, pp. 190-210. http://dx.doi.org/10.1108/14691930910952614 
Fritsch, M, Hackethal, A, Wahrenburg, M \& Wuellenweber, K 2007, 'The Impact of Business Process Outsourcing on Firm Performance and the Influence on Governance: A Long Term Study in the German Banking Industry', Available at SSRN: http://ssrn.com/abstract=1076422

Galbraith, JR 1977, Organization Design, Addison-Wesley, Reading, MA.

Goles, T \& Chin, WW 2005, 'Information systems outsourcing relationship factors: Detailed conceptualization and initial evidence', DATA BASE for Advances in Information Systems, vol. 36, no. 4, pp. 47-67. http://dx.doi.org/10.1145/1104004.1104009

Holweg, M. \& Pil, FK 2008, 'Theoretical perspectives on the coordination of supply chains', Journal of Operations Management, vol. 26, pp. 389-406. http://dx.doi.org/10.1016/j.jom.2007.08.003

Hong, Y, Pearson, JN \& Carr, AS 2009, 'A typology of coordination strategy in multiorganizational product development, International Journal of Operations \& Production Management', vol. 29, no. 10, pp. 1000-1024.

http://dx.doi.org/10.1108/01443570910993465

Krippendoff, K 1980, Content Analysis: An Introduction to its Methodology, SAGE, Newbury Park CA.

Langfield-Smith, K 2008, 'The relations between transactional characteristics, trust and risk in the start-up phase of a collaborative alliance', Management Accounting Research, doi:10.1016/j.mar.2008.09.001. http://dx.doi.org/10.1016/j.mar.2008.09.001

Laughlin, R 1995, 'Empirical research in accounting: Alternative approaches and a case for 'middle-range' thinking', Accounting, Auditing \& Accountability Journal, vol. 8, no. 1, pp. 63-87. http://dx.doi.org/10.1108/09513579510146707

Levie, J \& Lichtenstein, BB 2008, 'From “Stages” of Business Growth to a Dynamic States Model of Entrepreneurial Growth and Change', Working Paper, Hunter Centre for Entrepreneurship, University of Strathclyde.

Luft J \& Shields M 2002, 'Mapping Management Accounting: Graphics and Guidelines for Theory-Consistent Empirical Research', University of Michigan Papers.

Malmi, T \& Brown, DA 2008, 'Management control systems as a package-Opportunities, challenges and research directions', Management Accounting Research, Vol. 19, pp. 287-300. http://dx.doi.org/10.1016/j.mar.2008.09.003

Malone, TW \& Crowston, K 1994, 'The interdisciplinary study of coordination, ACM Computing Surveys', vol. 26, no. 1, pp. 87-119. http://dx.doi.org/10.1145/174666.174668

Mintzberg, H 1979, The Structuring of Organizations: A Synthesis of the Research, PrenticeHall, Englewood Cliffs, NJ.

Mouritsen, J 2006, 'Problematising intellectual capital research: Ostensive versus performative IC', Accounting, Auditing \& Accountability Journal, vol. 19, no. 6, pp. 820-841. http://dx.doi.org/10.1108/09513570610709881

Peirce, C 1959 Collected papers. The Belknap Press of Harvard University Press, Cambridge, MA.

Poppo, L \& Zenger, T 2002, 'Do Formal Contracts and Relational Governance Function as Substitutes or Complements?’, Strategic Management Journal, Vol. 23: pp. 707-725. http://dx.doi.org/10.1002/smj.249

Seal W, 2004, 'Towards an enabling research agenda for the accounting/contracting nexus', Accounting Forum, vol. 28, pp. 329-348. http://dx.doi.org/10.1016/j.accfor.2004.08.003

Simons, R 1990, 'The role of management control systems in creating competitive advantage: new perspectives', Organizations and Society, vol. 15, no. 1/2, pp. 127-143. http://dx.doi.org/10.1016/0361-3682(90)90018-P 
Sinha, KK \& Van de Ven, AH 2005, 'Designing Work Within and Between Organizations', Organization Science, vol. 16, no. 4, pp. 389-408.

Spekle, R 2001, 'Explaining management control structure variety: a transaction cost economics perspective', Accounting, Organisations and Society, vol. 26, no. 4-5, pp. 419-442. http://dx.doi.org/10.1016/S0361-3682(00)00041-6

Thompson, JD 1967, Organizations in Action, McGraw-Hill, New York, NY.

Tomkins, C 2001, 'Interdependencies, trust and information in relationships, alliances and networks', Accounting, Organizations and Society, vol. 26, no. 2, pp. 161-191. http://dx.doi.org/10.1016/S0361-3682(00)00018-0

Velez, ML, Sanchez, JM, Alvarez-Dardet, C 2008, 'Management control systems as interorganizational trust builders in evolving relationships: Evidence from a longitudinal case study', Accounting, Organizations and Society, vol. 33, pp. 968-994. http://dx.doi.org/10.1016/j.aos.2008.02.006

Vosselman, EGJ \& Meer-Kooistra, Jvd 2006, 'Changing the boundaries of the firm: Adopting and designing efficient management control structures', Journal of Organizational Change Management, vol. 19, no. 3, pp. 318-334.

Vosselman, EGJ \& Meer-Kooistra, Jvd 2008, 'Accounting for control and trust building in interorganizational transactional relationships’, doi:10.1016/j.aos.2008.04.002. http://dx.doi.org/10.1016/j.aos.2008.04.002

Whang, S 1992, 'Contracting for software development', Management Science, vol. 38, no. 3, pp. 307-324. http://dx.doi.org/10.1287/mnsc.38.3.307 